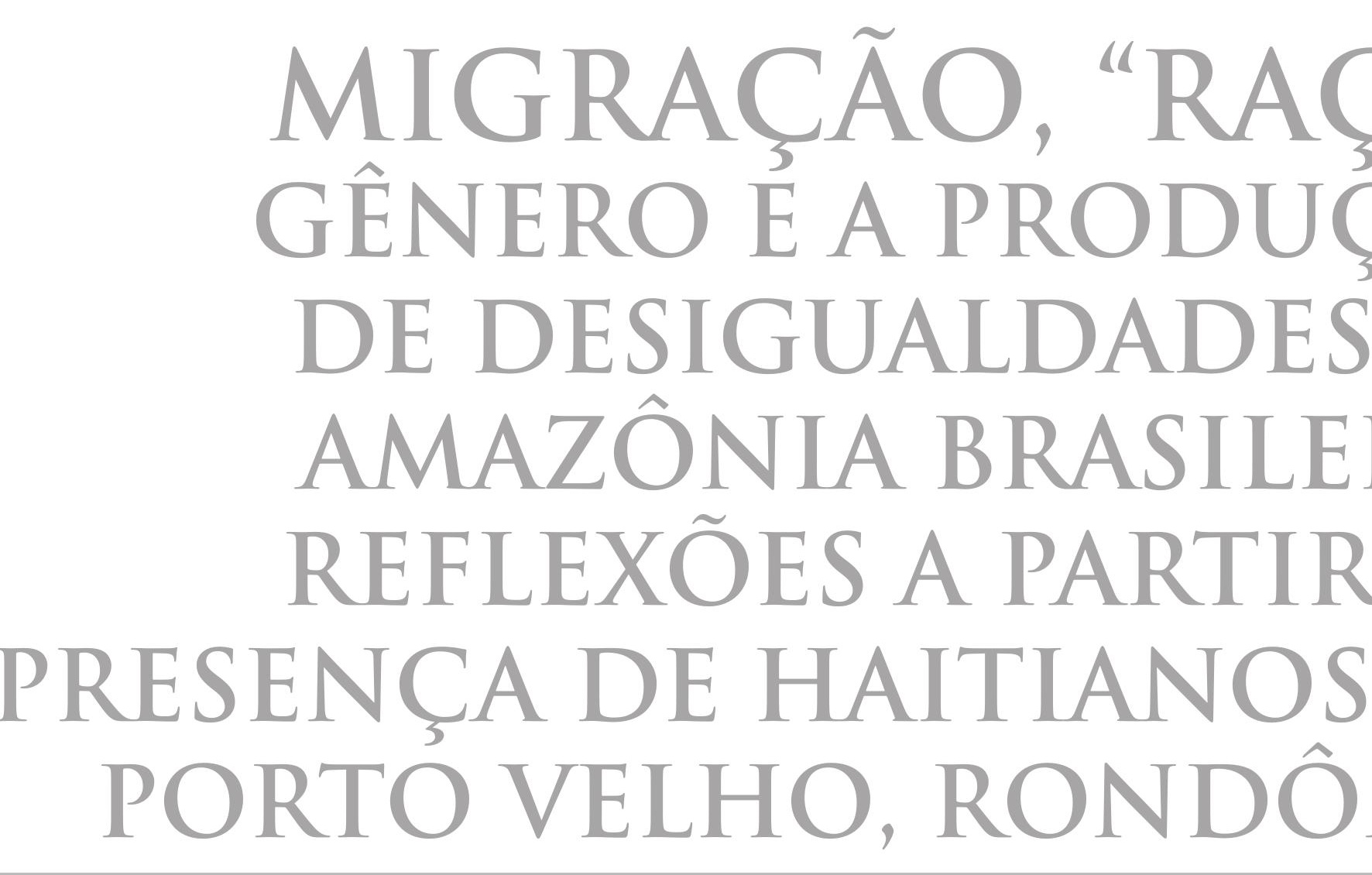




\section{MIGRAÇÃO, "RAÇA", GÊNERO EA PRODUÇÃ DE DESIGUALDADES NA AMAZÔNIA BRASILEIRA: REFLEXÕES A PARTIR DA PRESENÇA DE HAITIANOS EM PORTO VELHO, RONDÔNIA}

\section{WASHINGTON LUIZ DOS SANTOS ASSIS \\ UNIVERSIDADE FEDERAL DE RONDÔNIA - UNIR}

A DELIA MARIA MIGLIEVICH RIBEIRO

UNIVERSIDADE FEDERAL DO ESPÍRITO SANTO

E S T E VÃO RA F A E L F E R N A N D E S

UNIVERSIDADE FEDERAL DE RONDÔNIA - UNIR 
MIGRAÇÃO, "RAÇA", GÊNERO E A PRODUÇÃO DE DESIGUALDADES NA AMAZÔNIA BRASILEIRA: REFLEXÕES A PARTIR DA PRESENÇA DE HAITIANOS EM PORTO VELHO, RONDÔNIA

\section{Resumo}

À luz da imigração contemporânea de haitianos para a cidade de Porto Velho, Rondônia, este artigo pretende contribuir para a reflexão sobre a constituição e manutenção de desigualdades e hierarquias sociais na Amazônia a partir de marcadores sociais como imigrante, negro e mulher. Com este fim, este trabalho baseou-se em pesquisas de campo realizadas em Porto Velho, Rondônia, desde 2014, e pesquisas bibliográficas acerca da temática mais ampla. Marcada por constantes deslocamentos populacionais, a cidade de Porto Velho recebeu desde 2010 um grande número de imigrantes haitianos provenientes das fronteiras da Amazônia Ocidental brasileira e, posteriormente, em todo o Brasil em busca de trabalho e melhores condições de vida. A fim de compreender este fenômeno, bem como os dados produzidos ao longo da pesquisa, buscar-se-á, aqui, dialogar com autores pós-coloniais e decoloniais, como Frantz Fanon, Homi Bhabha, Kimberlé Crenshaw, Avtar Brah, Walter Mignolo e Anibal Quijano.

Palavras-chave: Migração, raça, gênero, pós-colonialismo, Haiti.

\section{MIGRATION, "RACE", GENDER AND THE PRODUCTION OF INEQUALIY IN THE BRAZILIAN AMAZON: REFLECTIONS FROM THE PRESENCE OF HAITIAN IN PORTO VELHO, RON- DÔNIA}
Abstract
In the light of the contemporary immigration of Haitians to the city of Porto Velho, Rondônia (Brazil), this article intends to contribute to the reflection on the constitution and mainte- nance of inequalities and social hierarchies in the Amazon from social markers such as immigrants, black and women. To this end, this work was based on field research carried out in Porto Velho, Rondônia, since 2014 and bibliographical research on the broader theme. Marked by constant population displacements, the city of Porto Velho has received since 2010 a large number of Haitian immigrants from the borders of the Brazilian Western Amazon and, later, throughout Brazil in search of work and better living 
conditions. In order to understand this phenomenon, as well as the data produced during the research, we will seek to dialogue with postcolonial and decolonial authors such as Frantz Fanon, Homi Bhabha, Kimberlé Crenshaw, Avtar Brah, Walter Mignolo and Anibal Quijano.

Keywords: Migration, race, gender, postcolonialism, Haiti.

\section{MIGRACIÓN, "RAZA", GÉNERO Y LA PRODUCCIÓN DE DE- SIGUALDADES EN LA AMAZONIA BRASILERA: REFLEXIO- NES A PARTIR DE LA PRESENCIA DE HAITIANOS EN PORTO VELHO, RONDÔNIA}

\section{Resumen}

A la luz de la inmigración contemporánea de haitianos en la ciudad de Porto Velho, Rondônia, este artículo pretende contribuir a la reflexión sobre la constitución y manutención de desigualdades y jerarquías sociales en la Amazonia a partir de marcadores sociales somo inmigrante, negro y mujer. Con este fin, este trabajo se basó en investigaciones de campo realizadas en Porto Velho, Rondônia, desde 2014, e investigaciones bibliográficas acerca de temáticas más amplias. Marcada por constantes desplazamientos poblacionales, la ciudad de Porto Velho recibió desde 2010 un gran número de inmigrantes haitianos provenientes de las fronteras de la Amazonias Occidental brasilera y, posteriormente, en todo Brasil, en busca de trabajo y mejores condiciones de vida. Con el fin de comprender este fenómeno, así como los datos producidos a lo largo de la investigación, se busca dialogar con autores poscoloniales y decoloniales como Frantz Fanon, Homi Bhabha, Kimberlé Crenshaw, Avtar Brah, Walter Mignolo y Anibal Quijano.

Palabras clave: Migración, raza, género, poscolonialismo, Haití.

Endereço para correspondência: Rua Quintino Bocaiúva, n. 2385. Bairro São Cristóvão. Porto Velho. Rondônia. Cep: 76804-052.

was.assis_unir@yahoo.com.br

miglievich@gmail.com

estevaofernandes@gmail.com 


\section{INTRODUÇÃO}

Como se constituem desigualdades e hierarquias sociais no Brasil? Os desdobramentos desta questão, à luz da imigração haitiana para a Amazônia brasileira motivaram este trabalho, construído a partir de etnografia realizada desde 2014 na cidade de Porto Velho, capital do Estado de Rondônia (ver figura 1).

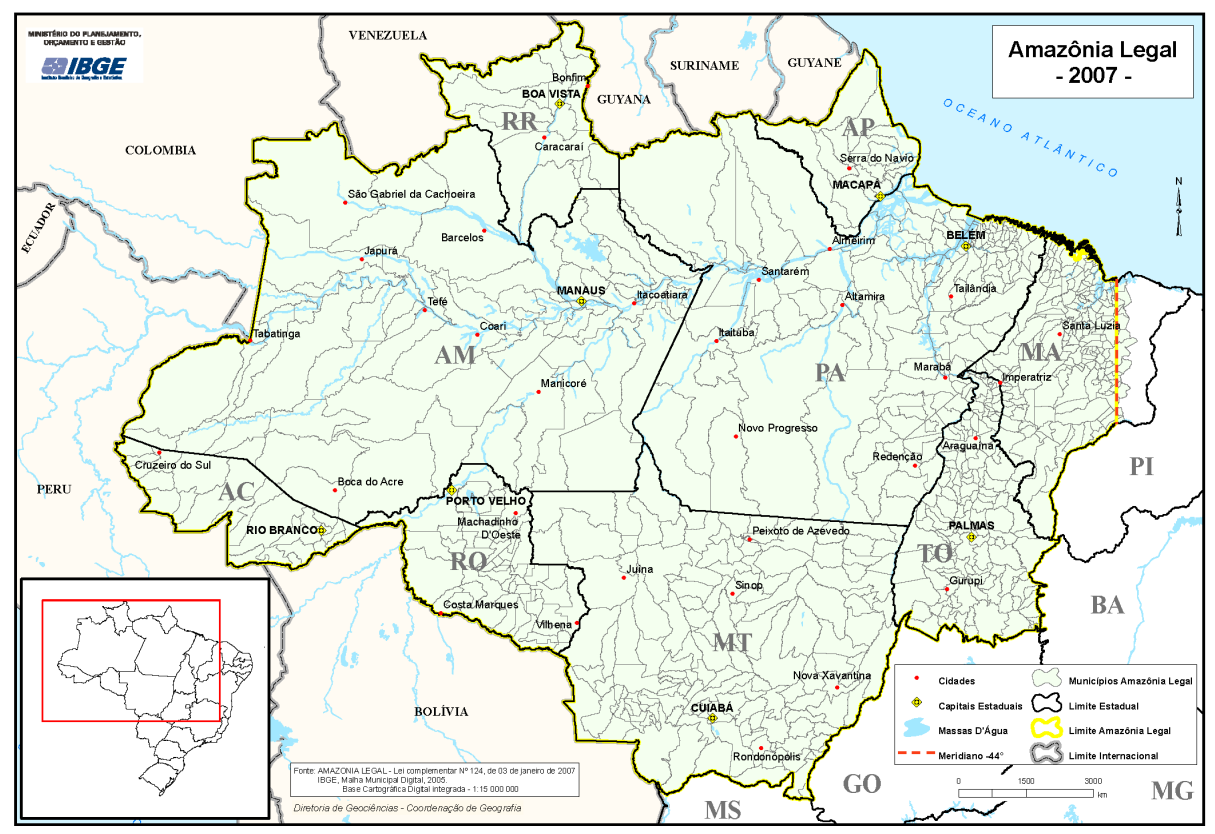

Figura 1: Localização geográfica do município de Porto Velho, estado de Rondônia, Brasil Fonte: Instituto Brasileiro de Geografia e Estatística

A cidade, criada durante a construção da Estrada de Ferro Madeira Mamoré (1907 a 1912), atualmente possui cerca de 500 mil habitantes. Constituiu-se historicamente sob influência de grandes ciclos econômicos, cada um responsável por um movimento migratório específico, destacando-se três: o "ciclo da Borracha" (1870 a 1945); o ciclo das minerações de cassiterita, pedras preciosas e ouro (1950 a 1990); e o ciclo das frentes de colonização agropastoris (1960 a 1990). As políticas desenvolvidas nesses ciclos volta- ram-se para a exploração, exportação ou transplantação de riquezas segundo as regras do mercado nacional e global, quase sempre de encontro aos interesses da população local e regional. As atividades agropastoris ainda permanecem em expansão na região, gerando muitos conflitos e antagonismos em virtude do desmatamento, da falta de controle ambiental e do grande número de territórios indígenas situados em localidades que passam a ser ambicionadas por diversos grupos e setores ligados ao agronegócio. 
Foi nesse cenário, marcado por deslocamentos populacionais e tensões políticas, que desde o ano de 2010 surge um novo fluxo migratório para região: a imigração transnacional haitiana, que pode ser percebida em quase todas as fronteiras da Amazônia ocidental. Uma imigração de características novas e específicas, cujas causas são tanto fatores culturais quanto os fenômenos sociais e econômicos causados pelos efeitos de uma globalização excluden$\mathrm{te}^{1}$. As principais cidades que registraram a entrada de imigrantes haitianos na região foram Tabatinga, no Estado do Amazonas, e Assis-Brasil e Brasiléia, no Estado do Acre (Cotinguiba \& Pimentel 2014:78). Muitos dos haitianos que entraram no Brasil nesse período se alojaram de forma precária nos abrigos improvisados organizados pelo governo do Acre.

Devido ao início das obras das usinas hidrelétricas do rio Madeira (Santo Antônio e Jirau), o governo do Acre convenceu muitos haitianos a seguirem para Porto Velho, onde um número considerável de imigrantes permaneceu, devido a uma maior oferta de empregos (Cotinguiba \& Pimentel 2014). A construção das usinas contribuiu para que a população de Porto Velho crescesse significativa mas desordenadamente, crescendo em mais de 100.000 habitantes, passando dos aproximadamente 380.000 para 511.219 habitantes, estimados atualmente (IGBE 2016) Um dos fatores que propiciaram o crescimento desordenado da cidade foi a má distribuição e utilização dos recursos de compensação recebidos pelo município devido à construção das barragens: os recursos financeiros que chegavam não eram devidamente aplicados em infraestrutura, saneamento, transporte público de qualidade e outras necessidades voltadas para a melhoria da qualidade de vida da população, em geral. Desta forma, os recursos privados passaram a ser direcionados para construção de moradias e atividades comerciais, gerando uma grande especulação imobiliária, aumentando ainda mais o custo de vida.

Com o término das obras e a redução do efetivo de trabalhadores nas usinas, a consequente queda na oferta de empregos pela cidade e a crise político-econômica iniciada no Brasil em 2015, a ilusão de "progresso" logo se desfez. Isso contribuiu para que muitos haitianos deixassem a cidade e até mesmo o país, em sua maioria, por meio da mesma rota utilizada para a entrada, no entanto, agora em sentido contrário, realimentando as esperanças de chegarem a países ricos, ou com a economia mais sólida, como os Estados Unidos e, noutra ponta do continente, o Chile, onde alguns interlocutores dessa pesquisa se encontram hoje.

Apesar das dificuldades e do agravamento da situação político-econômica do Brasil, alguns haitianos permaneceram em Porto Velho. Assim, o aumento do desemprego e, consequentemente, da disputa no mercado de trabalho, fez com que alguns haitianos discriminados na área de prestação de serviços - que tende a selecionar outros "perfis" de empregados para compor seus quadros de funcionários, baseados no critério "racial" da "boa aparência" -, 
passassem a trabalhar informalmente como ambulantes nos semáforos da cidade.

Assim sendo, nossa análise detém-se em refletir sobre as desigualdades de "raça" e de gênero, que persistindo na sociedade brasileira, são também experimentadas em vários níveis, e de diferentes formas, pelos imigrantes haitianos e haitianas. Esses marcadores sociais ("raça" e gênero) potencializam a respectiva condição de subalternidade que está inextricavelmente ligada à colonialidade, face oculta da modernidade. Nesse sentido, o "giro decolonial" (Maldonado-Torres, 2006) passa a ser o desmascaramento do projeto de dominação cultural (e econômica) sob a aparência de "missão salvacionista" dos primeiros tempos do colonialismo. Também das ideologias do "desenvolvimento" e do "progresso" que, alinhadas à retórica ocidental (liberal ou marxista), produzem a "inexistência" de povos e etnias, sua dessubjetivação, que podem facilmente ser observadas nas situações analisadas neste artigo.

\section{DUAS SOCIEDADES MARCADAS PELA "RAÇA"}

As concepções em torno da ideia constituída de "raça" na formação do imaginário social de brasileiros e haitianos, embora possuam gêneses distintas, apresentam grande influência da ideologia difundida pelo colonialismo no sistema-mundo a partir do século XVI, tornando-se assim, um dos princípios organizadores das estruturas de ambas as sociedades (Grosfoguel 2008), cada uma com suas peculiaridades. Também Immanuel Wallestein (2006) é assertivo ao apontar a importância fundamental do racismo (e do sexismo) como um dos principais vetores do sistema histórico ou economia-mundo capitalista. Aníbal Quijano (2010), similarmente aos autores anteriores, concorda que a colonialidade é um dos elementos constitutivos do padrão mundial do poder capitalista, sabendo que este se sustenta na imposição de uma classificação étnica/racial da humanidade.

Enquanto no Brasil as estruturas sociais foram grandemente definidas segundo as teorias evolucionistas (eugenistas e darwinistas sociais), utilizando-se os fenótipos como cor da pele, textura dos cabelos e outros sinais físicos visíveis (Quijano 2000) para constituir diferenciações e hierarquizações e, consoante a tais teorias, a distância ou a proximidade com os marcadores "brancos" aprofundavam ou minimizavam o preconceito "racial", no Haiti - por se constituir uma república negra - a "racialização" das relações sociais se conformou de forma diferente, não por uma diferenciação biologizada e sim classista (Handerson 2015). Para a sociedade haitiana, as categorias negro e mulato não são compreendidas como categorias raciais e sim como classes sociais, pois, independente do fenótipo que possui, todo cidadão haitiano é compreendido como sendo negro (nèg) (Glick-Schiller \& Fouron 1997).

"Porque se o filho ilegítimo de uma trabalhadora negra com um ma- 
rinheiro branco que visita o porto poderia descrever-se como um mulâtre em aparência, com certeza não o consideraria como membro da classe mulatre (a superior). Ao contrário, um alto funcionário do Governo, ou um homem negro próspero de negócios, se asseguraria como mulâtre casando-se com uma guria da classe mulâtre" (Handerson, 2015, p. 541).

Neste sentido, a diferença entre ser negro e ser mulato no Haiti é uma questão de hierarquia e categoria social, enquanto ser branco está relacionado - dentre outros fatores - a um conjunto de comportamentos sociais e culturais distintos, aqueles esperados pelas sociedades ocidentalizadas, cujos parâmetros são, invariavelmente, valores e costumes eurocêntricos.

Segundo Ballestrin (2013:101), “a identificação dos povos de acordo com suas faltas ou excessos é uma marca fundamental da diferença colonial, produzida e reproduzida pela colonialidade do poder". Essas faltas e excessos foram verificados na constituição de desigualdades relacionadas às inter-relações de imigrantes haitianos e brasileiros em Porto Velho. Isso por que a lógica racista imposta pelo sistema colonial segue permeando o imaginário social desses dois grupos mesmo que de forma distinta e peculiar, fazendo com que nas interfaces dessa relação os imigrantes haitianos sejam deslocados para zonas periféricas de "não-poder" e "não-ser".

Como exemplo dessa relação de poder e discriminação, transcrevemos a seguir o trecho de uma entrevista gravada com um imigrante haitiano em junho de 2015:

"Eu estava trabalhando para uma empresa que chamava Virtual, que prestava serviço pro Gerencial, um cara, todo dia, ele está me xingando.

Eu era ajudante e ele era profissional.

Um dia não aguentei, eu chegar e falar: cara, eu vem aqui no Brasil e eu tenho dois motivos....

... Aí ele nem deixa en falar e diæ: você tem motivo nenhum, você está é no seu país passando fome.

Ai eu respondi: Ob! Cara vou falar sério pra tu, vambora acabar com isso boje...

Então fui procurar o engenheiro pra falar, mas tive dificuldade porque não era bem assim que en falava, faltava palavra para explicar...

Ai ele [engenheiro], na tentativa de amenizar a situação, falou assim para mim: "eu gosto muito de você, vocêe é trabalhador. É estrangeiro, é NEGRO CLARO...".

E eu falei! Como assim?

Não tem isso não engenheiro, negro é negro!"

No diálogo apresentado, podemos perceber que o haitiano sofre quatro formas distintas de discriminação, a primeira por sua origem étnica e nacional (ao tentar falar para o colega de trabalho os motivos de sua estada no Brasil, uma vez que é oriundo de um país empobrecido $)^{2}$ a segunda devido a classe social que lhe é atribuída (sujeito-imigrante e subempregado), a terceira pela dificuldade com o manejo da língua portuguesa (que fragiliza seu discurso em autodefesa) e a quarta diretamente por questões raciais, motivadas pelo perverso mito da "democracia racial" presente no 
imaginário social brasileiro ao ponto de, ao final da conversa, o engenheiro chamar o haitiano de "negro claro", deixando subentendido seu critério de aceitabilidade e sua expectativa de comportamento social desejável de um sujeito na sociedade brasileira, que estaria relacionada à cor de sua pele, ou seja, quanto menos negro (ou mais branco) mais aceitável socialmente (Skidmore 1976).

$O$ fato de o haitiano ser chamado "negro claro" tem grande relação com a política de branqueamento da população, difundida no Brasil no final do século XX, cujo objetivo era branquear a população brasileira em até três gerações. Segundo a antropóloga Lilia Moritz Schwarcz (2007:12), "o branqueamento foi uma espécie de jeitinho brasileiro para resolver a questão ontológica das raças sem a condenação da hibridização, uma vez que o país estava irremediavelmente miscigenado", surgindo como solução para os "problemas de cor" da população brasileira, pois acreditar que os problemas da negritude física e cultural do brasileiro seriam "resolvidos" em até três gerações era o que a elite mulata do país mais precisava à época. Suas consequências podem ser percebidas nas relações sociais até os dias atuais.

Outra medida tomada para equalizar a questão do branqueamento aos supostos interesses da elite brasileira foi a adoção, por parte dos governantes, de medidas seletivas de imigração, nas quais a regulação e a seleção de imigrantes se davam por caracteres físicos tornando-os mais, ou menos desejados, a depender de critérios "raciais" e étnicos (Skidmore 1976).

\section{"RAÇA", ETNIA E IMIGRAÇÃO NA SOCIEDADE BRASILEIRA}

Compreender o fenômeno da imigração no contexto brasileiro requer entender que, apesar de sua formação pluriétnico-"racial", o Brasil está repleto de histórias e registros de decisões políticas restritivas e impeditivas do acesso de determinados sujeitos ao território nacional, classificados, desde então, como "indesejáveis". Os parâmetros de seleção giravam em torno, como já assinalado anteriormente, de caracteres físicos, culturais e étnicos, dividindo os sujeitos em imigrantes assimiláveis ou não-assimiláveis.

Séculos de discursos político-ideológicos de discriminação contribuíram para que se formasse no imaginário social brasileiro a ideia de imigrantes bons/maus, aceitáveis/não aceitáveis, assimiláveis/não-assimiláveis, os quais eram determinados por critérios como "raça", etnia e origem nacional, excluindo os "cidadãos de cor" dos espaços de aceitabilidade social (Skidmore 1976).

Em virtude de o Brasil ter se tornado um país multirracial, as discriminações sofridas pelos "sujeitos de cor" nem sempre encontravam ressonância nos discursos sociais. Fortaleceu-se, assim, a aparência de que os diferentes povos e "raças" representados no país vivessem em constante harmonia. Mas, como uma sociedade formada com bases patriarcais e escravocratas 
poderia formar uma sociedade igualitária? Como poderia haver no Brasil uma verdadeira "democracia racial"?3

Nesta perspectiva, cabe ressaltar o lugar do Teatro Experimental do Negro (TEN) no debate da questão racial no Brasil, criado em 1944 sob a liderança de Abdias Nascimento. O TEN se propunha a atualizar a luta política dos negros da década de 1930, representada então, emblematicamente, pela Frente Negra Brasileira. De movimento cultural, o TEN politizava-se gradativamente no processo de democratização do país no pós-guerra, influenciado pela luta mundial contra o racismo e pela eclosão das guerras de libertação nacional em África. Controvérsias acompanharam a vida do TEN que se equilibrava entre a afirmação política da identidade negra e a aposta na assimilação do negro na nação brasileira mediante o acesso à educação e a conquista de direitos.

Segundo Marcos Chor Maio (1997), o sociólogo negro Guerreiro Ramos, que se engajou ao TEN em fins da década de 1940 e inícios de 1950, postulava que o racismo no Brasil deveria ser encarado a partir das diferenças regionais, de classe e da clivagem rural/urbano. Em sua percepção, o preconceito em relação ao negro seria de cor e não de "raça", o que implicava sua aposta na ascensão social da população negra no Brasil. Por fim, criticava a "folclorização" do negro pelas ciências sociais em geral, e pela antropologia em particular. Maio (1997) dedica-se a narrar que marcam os anos 1950 também as pesquisas sobre as relações raciais no
Brasil patrocinadas pela UNESCO. Realizadas em Pernambuco, Bahia, São Paulo e Rio de Janeiro, atraindo um grande grupo de cientistas sociais, que abandonam em definitivo o pensamento ainda em voga nos anos 1930 de que haveria qualquer associação determinista entre características "raciais", comportamentos sociais e atributos morais. O mesmo grupo reconhecia, porém, a discriminação racial no Brasil, frustrando, em larga medida, a expectativa inicial da UNESCO, que pretendia encontrar em solo brasileiro a tal "democracia racial" imaginada como um antídoto à barbárie da Segunda Guerra Mundial.

O debate público acerca da questão racial continuava restrito. A ideologia nacional-desenvolvimentista em vigor não era totalizadora, mas tendia a subestimar algumas pautas. Noutro espectro, a polarização direita x esquerda tendia a tornar o racismo para os marxistas uma problemática se não "menor", passível de adiamento, um erro de análise, como se perceberia mais tarde, consequente. Entre 1964 e 1986, o Brasil sofreu mais uma vez a ditadura que veio, também, a esvaziar as lutas sociais, sobretudo, a partir do aprofundamento da repressão com o AI-5 de 13 de dezembro de 1968.

Os fins dos anos 1970 chegam com a luta pela redemocratização política e, no contexto dos movimentos sociais, surge o Movimento Negro Unificado que vem constatar o "caráter negro da desigualdade" no Brasil e define o debate dos anos 1980.

"De fato, o que nos anos 80 e 90 desenhava-se no horizonte das 
lutas antirracistas no Brasil era uma constatação política de grande peso: que não unicamente os que ocupam os estratos sociais inferiores são fundamentalmente afro-brasileiros, senão que a desigualdade aludida é persistente. Ao compararem-se diferentes gerações de brancos e negros, um branco teria maiores possibilidades de ascensão social que um negro, inclusive quando os pais de ambos apresentam níveis socioeconômicos parecidos" (Gadea 2013:321).

A temática racial passou a ganhar mais espaços nos debates acadêmicos e sociais comprometidos em descortinar o racismo brasileiro. Os chamados "estudos raciais" afirmavam que as desigualdades sociais podiam ser explicadas por variáveis como cor e "raça" e isto promovia, gradativamente, a derrubada da tese da "democracia racial" no Brasil.

No ano em que se completaram cem anos de abolição da escravatura um grupo de pesquisadores da Universidade de São Paulo (USP) organizou um survey para analisar a vigência do preconceito racial, na pesquisa as pessoas foram perguntadas se elas tinham preconceito de cor e se conheciam alguma pessoa que tivesse. O resultado da pesquisa foi inesperado, pois ao mesmo tempo que $97 \%$ dos entrevistados responderam que "não", não tinham preconceito de cor, 99\% diziam conhecer alguém que o tivesse (Schwarcz 2009).

A conclusão dessa pesquisa foi que "todo brasileiro se sentia como uma ilha de democracia racial, cercado de racistas por todos os lados" (Schwarcz 2009:7), reforçando o pressuposto de que não existe uma democracia racial no Brasil, e sim um racismo velado ou, como se tende a dizer hoje, cada vez mais explicitado uma vez que se começa a prestar atenção a este.

No entanto, quando o sujeito é um imigrante excluído do acesso a direitos básicos, as relações sociais e os preconceitos se mostram sempre mais evidentes, fazendo com que alguns cidadãos nacionais se permitam externar seus sentimentos racistas, discriminando, como a pesquisa demonstra, imigrantes haitianos (negros) em Porto Velho. Isto expõe, uma vez mais, como a sociedade brasileira apesar de sua formação pluriétnico-racial mantém-se racista. Pois, "defendemos, de uma vez por todas, o seguinte princípio: uma sociedade é racista ou não o é" (Fanon 2008:85).

Durante o campo, foi possível observar muitas dessas situações racistas, das quais, selecionamos algumas para compreender como estão se dando as relações envolvendo haitianos e habitantes locais. A princípio, tais discriminações apresentam-se de forma velada e sutil, geralmente, subscrita em manifestações descontraídas, brincadeiras desprestigiantes e/ou apelidos e chamamentos depreciativos. Dependendo, porém, dos interesses "em jogo", o racismo abandona quaisquer disfarces e se torna direto.

\section{ESCUTANDO SILÊNCIOS: QUANDO O "SUBALTERNO" FALA}

As formas como são constituídas as relações de poder e dominação nas so- 
ciedades modernas (ocidentalizadas) fazem com que assujeitados e excluídos adotem o silêncio como uma ferramenta de defesa e/ou (auto)proteção, contra as agressões que sofrem por conta de suas diferenças. Para a crítica pós-colonial indiana, Gayatri Spivak (2010), a incapacidade de serem ouvidos e compreendidos por uma audiência externa, reforça-se o silêncio que condena a "alteridade" ao emudecimento e à invisibilidade.

A utilização desses mecanismos por parte dos imigrantes haitianos foi percebida em nossas pesquisas a partir de um conjunto de diálogos e entrevistas realizadas com haitianos e colaboradores de Porto Velho, em momentos e espaços distintos. Neste sentido, destacamos a entrevista realizada com uma graduanda em Letras da Universidade Federal de Rondônia, em Porto Velho, professora de gramática da língua portuguesa para imigrantes haitianos em um projeto da Universidade. Em seu relato, ela informa que em uma de suas aulas com os imigrantes, solicitou que os alunos haitianos trouxessem para a aula seguinte palavras ou frases que ouvissem durante a semana e fossem desconhecidas por eles, com a finalidade de contextualizá-las e ensinar-lhes seus significados. Uma dessas expressões foi trazida por um aluno que, bastante curioso, entregou-lhe por escrito em um papel o termo, negão-pau-no-cut.

De acordo com a professora, aquela expressão lhe causou tanto tristeza quanto embaraço, pois ela não sabia como iria explicar o significado daquelas palavras para o haitiano, posto que se tratava de um xingamento de mora- dores locais (nacionais), buscando humilhar aquele imigrante, provavelmente em seu ambiente de trabalho.

O relato acima reforça um pressuposto de que marcadores sociais da diferença - neste caso específico, notadamente o de "raça" - eram acionados como estigmas (Goffman 2004) a fim de afirmar a subalternidade de imigrantes haitianos em variados contextos sociais. Fez-se de forma covarde o uso da linguagem como ferramenta de discriminação, ao se aproveitar do pouco léxico que esses sujeitos possuíam para destratá-los e humilhá-los.

Nessa mesma perspectiva, surge outro relato, no qual um de nossos interlocutores, residente por mais de cinco anos no Brasil, reforça o argumento de que alguns brasileiros se utilizam da falta de entendimento que muitos haitianos têm do idioma português para manifestarem atitudes e sentimentos racistas por meio de palavras. No entanto, quando essas pessoas começam a compreender o que se fala, geralmente, sentem-se bastante entristecidos. Segundo o entrevistado:

"Tem baitiano que está sofrendo preconceito e não sabe, o cara está xingando baitiano e ele não sabe. O haitiano vai comprar uma coisa, e se a pessoa não entende já xinga o haitiano. Às vezes eu acho melhor quando o haitiano não entende, porque se entende, se sabe o que fala, dói muito. É melhor quem não entenda e quem não fala português, porque quando você entende machuca".

Podemos perceber como a falta de domínio da língua pode se tornar uma ferramenta de opressão diante da qual o outro sequer pode se defender, ca- 
paz não apenas de subalternizar os diferentes, mas também de inferiorizá-los, desconhecendo sua condição de humanidade (Fanon 1980). Desloca-se aquele que é dessubjetivado e "animalizado" para as zonas sociais periféricas, as chamadas de zonas intersticiais de "não-ser" e "não-poder", ou seja, os espaços destinados àquele que remete a diferença às marcas coloniais que produziram e produzem a "diferença colonial" como subalternidade, a qual, em suas articulações, amplifica a condição de desigualdade e subalternidade.

Homi Bhabha (2013), crítico pós-colonial indiano, compreende o estigma ou estereótipo como uma fantasia que constrói inevitavelmente uma imagem redutora dos sujeitos. Nesse sentido, o estigma, antes de ser uma falsa representação da realidade (é também), implica uma redução ou mutilação da realidade. Ao reduzi-la e simplificá-la, falseia-a, por tentar aprisioná-la numa forma fixa que recusa o jogo das distinções e das semelhanças, a condição de sermos, todos, seres múltiplos e incompletos, capazes de identificações e atuações incontáveis. É, em verdade, a negação do "outro" mediante sua reificação, com graves efeitos na constituição psíquica e social dos membros da interação (Bhabha 2013:130).

Como diz, também, o filósofo canadense Charles Taylor (2000), a negação do reconhecimento ou o reconhecimento equivocado dos sujeitos traduz-se numa "ferida moral" consequente na constituição da identidade de pessoas, coletividades e povos. Não é algo casual se a imagem que temos devol- vida de nós mesmos nos reduza, nos desmereça ou nos despreze. Tal imagem depreciativa é encapsuladora e tem o poder de nos fazer nela acreditar, o que significará uma real distorção da personalidade. Em sentido oposto, o justo reconhecimento não é uma mera cortesia: "é uma necessidade humana vital” (Taylor 2000:242).

Outra forma de subordinação interseccional que aparece nos relatos de nossos interlocutores faz alusão à origem étnico-nacional (cultura) desses sujeitos. As falas das pessoas demonstram que certos brasileiros discriminam imigrantes haitianos tanto por sua nacionalidade, em articulação com o marcador social de "raça", quanto por sua pele (preta), em articulação aos estigmas de classe social (devido à situação econômica do Haiti).

Essas articulações dificultam, sobremaneira, a percepção do "local" de origem dessa produção de desigualdade. Uma vez articulados, os efeitos da discriminação potencializam-se formando um único e novo elemento discriminador, com efeito de deslocamento social bem maior.

Nesse sentido, as discriminações realizadas por questões de origem étnico-nacional podem ser facilmente confundidas com a discriminação motivada por questões raciais e/ou de classe social, isso, pelo motivo do Haiti ser conhecido mundialmente como sendo uma nação negra e empobrecida, carregando o estigma de país mais pobre das Américas, o que coloca os imigrantes desse país em situações menos confortáveis ainda. 
Para contextualizar nossa argumentação, segue abaixo o relato de um de nossos interlocutores:

"Os brasileiros falam muito da gente e do país da gente. Eu sei que eu não sou brasileiro (...). O que é que tem a ver o Haiti? Nós está aqui, você já está com preconceito com a gente. Não precisa falar mal do país da gente, eu sei aqui não é nosso país. Não pode julgar pessoa pela cor e pelo pais, tem que ser pelo que ele é".

Pode-se notar no trecho acima como a relação de convivência entre habitantes locais e imigrantes haitianos se apresentam de forma socialmente conflituosa, fazendo com que quase sempre esses sujeitos tenham que se silenciar. A "obrigação de ser reservado" é como um sinal de "neutralidade", que segundo Abdelmalek Sayad, é "a forma de polidez que o estrangeiro deve adotar e que ele se sente na obrigação de adotar" (2000:57) para evitar "problemas". Em geral, causados pela não aceitação de suas diferenças gerando uma série de discriminações que agem de forma articulada, reunindo "raça", classe, nacionalidade, e até mesmo gênero como veremos adiante.

\section{GÊNERO, "RAÇA" E IMIGRAÇÃO: DIFERENÇAS SOCIAIS EM ARTICU- LAÇÃO}

A naturalização das diferenças de gênero na sociedade brasileira se faz presente pela constituição de diferenciações significativas nas relações sociais. Nelas, a distribuição desigual de vantagens e desvantagens recebem influências de uma estrutura patriarcal e escravocrata, característica de sociedades coloniais.
Isso se verifica também no Brasil, onde mesmo após a independência política e a abolição da escravatura, tal estrutura ainda permeia a sociedade, atingindo as mulheres não apenas pela naturalização das diferenças de gênero, mas também pelas articulações de marcadores tais como raça e classe, de forma interseccional e articulada, gerando interstícios nos quais as diferenciações são aparentemente "normais" e muitas das vezes até "aceitáveis".

É nesse contexto social que analisamos as situações ocorridas com três mulheres haitianas: Mary, Suzan e Francine ${ }^{5}$, cujos percursos a serem apresentados nos possibilitarão o desenvolvimento de algumas questões sobre intersecções e articulações de gênero no Brasil.

Mary é uma imigrante haitiana que trabalhou como diarista em uma residência em Porto Velho e, após uma semana de trabalho, não recebeu a quantia correspondente à atividade por ela desenvolvida. Suzan, por sua vez, é uma haitiana que chegou ao Brasil com duas filhas, ambas maiores de idade; a mulher, de aparentemente 35 a 40 anos de idade, trabalhava como cozinheira de uma lanchonete bastante conhecida na cidade. Além de desenvolver atividades na cozinha, Suzan também gerenciava o salão de atendimento aos clientes, tendo sob sua responsabilidade dois ou três garçons, dependendo do movimento da lanchonete. Todavia, mesmo com os acréscimos de responsabilidade, ela recebia um salário significativamente inferior aos dos garçons (homens e brasileiros). Em sua prática diária, Suzan, pela lógica, deveria receber um salário maior que o dos fun- 
cionários subordinados a ela, o que na prática não ocorria. A terceira história que iremos abordar é a de Francine, professora de idiomas com experiência no ensino das línguas francesa e espanhola. Pedagoga de formação no Haiti, com aproximadamente 30 anos de idade, residiu em Porto Velho por aproximadamente nove meses, mas, por não conseguir emprego em sua área, teve que se mudar para outro estado da federação, Mato Grosso, onde viveu até meados de 2016 com a ajuda de parentes e amigos ${ }^{6}$, e ainda assim, não conseguiu emprego em sua de formação.

Analisemos então cada um dos casos buscando uma melhor compreensão da constituição das diferenças sociais, não somente através da categoria "gênero", mas a partir dela. Observaremos sua articulação com outras categorias que, em suas combinações, (re)produzem novas formas de desigualdade.

Por se tratar de questões de gênero, para nossas ilações recorreremos a alguns estudos desenvolvidos pelas feministas Kimberlé Crenshaw (2002; 2004), Avtar Brah (2006) e Adriana Piscitelli (2008), cujas contribuições foram sobremaneira importantes para o desenvolvimento das análises sobre a articulação ${ }^{7}$ de categorias como gênero, "raça", classe e imigração.

Nesse sentido, Piscitelli (2008) aponta que, para algumas antropólogas e estudiosas feministas, a compreensão de gênero, a partir da cultura ocidental, traduz nas relações entre os sexos, as relações cultura e natureza, razão e emoção, civilização e barbárie, nas quais, se deve levar em consideração a teoria do poder político e suas especificidades, sobretudo, as relações de dominação e subordinação, exploração, coerção, controle e desigualdade. Não é gratuito que o chamado feminismo decolonial proponha uma descolonização do pensamento mediante a ruptura dos binômios modernos em prol de uma realidade diversa, porque híbrida. Como indica Costa,

"[...] a possibilidade, primeiro, de abrir espaços para um tipo de pensamento que nos permite desaprender/desfazer a violência ontológica representada pelo dualismo natureza/cultura (nos permitiria "desacelerar a reflexão"); e, num segundo, entender que há diferentes perspectivas de diferentes mundos - e não visões diferentes de um mesmo mundo" (Costa 2014: 96).

A contribuição da socióloga e feminista Kimberlé Crenshaw (2004:9) faz a interface com a questão racial apontando como "homens e mulheres podem experimentar situações de racismo de maneiras especificamente relacionadas a seu gênero", ou seja: se o objeto de discriminação racial são mulheres, o racismo sofrido por elas pode ser potencializado pelas práticas sociais de uma sociedade patriarcal, como é o caso brasileiro. Já Avtar Brah (2006:331), de modo semelhante, argumenta "que a análise das interconexões entre racismo, classe, gênero (...) ou qualquer outro marcador da "diferença" deve levar em conta a posição dos diferentes racismos entre si", que, nos casos citados aqui, estão representados pelas relações gênero e "raça", gênero e classe, gênero e "origem", classe e "origem", e assim por diante. 
Por essa perspectiva, percebeu-se que as desigualdades sociais analisadas por meio de categorias isoladas não dariam conta de explicar as situações vividas por nossas interlocutoras (haitianas) em seus ambientes de trabalho. Optou-se, assim, por analisá-las nas articulações e interseccionalidades construídas desde a categoria gênero, posto que as "estruturas de classe, racismo, gênero e sexualidade não podem ser tratadas como 'variáveis independentes' porque a opressão de cada uma está inscrita dentro da outra - é constituída pela outra e é constitutiva dela" (Brah 2006: 351).

As histórias de Mary, Suzan e Francine evidenciam como a articulação de determinados marcadores sociais, ao se associarem à categoria gênero, constituem epistemologias e práticas sociais que potencializam as condições de desigualdade da mulher, subalternizando-a e limitando-a ainda mais, reduzindo consideravelmente sua agência.

Ademais, os efeitos causados por essas articulações variam de acordo como são pensadas as diferenças sociais no seio de cada sociedade. Nesse sentido, compreender os fatos históricos, políticos e sociais é de fundamental importância na apreensão do fenômeno da subalternização em sua ampla gama de situações.

Em uma sociedade machista, patriarcal, racista, classista e xenofóbica, é comum que nem todas as mulheres sofram o mesmo grau de discriminação, tendo em vista que nessa sociedade, a produção de desigualdades que afetam uma mulher negra, estrangeira e pobre serão sempre maiores do que as que impactam uma mulher branca, nacional e de posses. Isto nos remete ao entendimento de que quanto maior for o número de diferenças corporificadas nessas mulheres, maior será o seu deslocamento na sociedade.

A utilização dos métodos de articulação das diferenças e intersecções para a análise do caso das três haitianas foi de fundamental importância para que compreendêssemos como a confluência de múltiplas diferenciações pode resultar em uma nova (e mais danosa) forma de desigualdade social na região, que passa a não se tratar apenas da discriminação de uma só marca colonial, mas do somatório de todas as marcas corporificadas nesse "sujeito da diferença", que deixa de ser "sujeito", experimentando a subalternidade e o deslocamento ainda maiores.

Assim, compreendemos que o fato da diarista Mary - mesmo após várias tentativas - não ter recebido a quantia referente aos seus dias trabalhados não estava relacionada apenas à questão de ela ser imigrante haitiana nem negra mas, também, ao fato de ela ser mulher. Quando um de seus conterrâneos (do sexo masculino) foi à residência do empregador realizar a cobrança dos serviços prestados por Mary não encontrou muita resistência para obter o pagamento devido.

De igual modo, as situações ocorridas com Suzan e Francine seguem a mesma lógica de subalternização articulada nas relações de trabalho brasileiras: a discriminação de empregados imigrantes não se dá, apenas, por questões 
salariais, mas também funcionais, das quais a maior ou menor remuneração seria em tese decorrente. $\mathrm{O}$ fato de um funcionário ocupar a função de chefia, mas não ter esta denominação, logo, não receber salários compatíveis ao exercício de sua efetiva função só ocorre com mulheres, configurando discriminação por gênero. Por esse motivo, a condição imigrante haitiana de Suzan não seria suficiente para justificar seu baixo salário dada a função que a haitiana realizava na lanchonete. Ademais, de uma forma geral, os baixos salários dos imigrantes no Brasil geralmente estão relacionados aos empregos ditos de segunda categoria (serviços insalubres e extenuantes), "destinados" para pessoas oriundas das margens da sociedade local e/ou imigrantes.

Em relação à Francine, - além de maior - o deslocamento social sofrido se torna bem mais evidente visto que, nesse caso, as categorias mulher e imigrante são potencializadas pelas influências das categorias "raça" e classe. Mesmo com curso superior em pedagogia - realizado no Haiti - e certificado de proficiência linguística (DELF) emitido pela Aliança Francesa, a haitiana ficou desempregada por quase nove meses em Porto Velho. A situação poderia ser compreendida como normal se a carência de professores do idioma francês na cidade não fosse grande como tem se apresentado. Ademais, em diversos cursos de línguas na capital, encontramos professores estrangeiros, no entanto, de origem europeia (bran$\cos$ ), dos quais tivemos a oportunidade de conversar com um professor irlandês e uma professora espanhola.
Nossa análise exibe um contexto de deslocamentos, poder e subalternização do qual emergem as teorias pós-coloniais, exercendo uma profunda influência na reconfiguração dos saberes e das epistemologias padrão. Por excelência, as teorias feministas pós-coloniais (e decoloniais) trazem para o centro do debate a questão da racialização da subalternidade. Não somente uma vez que as mulheres que lhes servem como mote de reflexão são aquelas que habitam o "entre-lugar" (Bhabha 2013), a fronteira, as migrantes e deslocadas. Não é casual que, na construção do pensamento feminista latino-americano, veja-se uma profunda articulação entre a questão da colonialidade do poder e do ser. Aqui, por excelência, a hibridez destaca o terreno das diferenças, da interseccionalidade e das múltiplas "mestiçagens", tal como na poética feminista de Anzaldúa, que propõe, ao fim, um discurso que faça um apelo à liberdade para a diferença ${ }^{9}$.

\section{CONSIDERAÇÕES FINAIS}

As reflexões desenvolvidas neste artigo indicam-nos que diferenças entre os sujeitos não devem e nem podem ser compreendidas como um fenômeno de ações desconexas entre si, tampouco descoladas das relações de poder nas quais estas diferenças são construídas e consolidadas. Os subalternizados portadores de diferenças múltiplas não o são por conta de uma única marca colonial, mas pela confluência de todas as marcas existentes, formando o não-ser assujeitado nos domínios daquelas diferenças - os chamados "entre-luga- 
res", nos excedentes da soma das "partes" da diferença, geralmente expressas como raça/classe/gênero (Bhabha 2013:20). Trata-se da diluição do lugar de enunciação desses sujeitos, que tenta tornar nulo seu espaço de contraposição e - resistência - existência.

Em seus efeitos, essas articulações têm limitado significativamente a condição de agência desses imigrantes haitianos, embora não a faça desaparecer sobretudo em se levando em conta suas estratégias de autoproteção e sua sobrevivência mesma em condições que não poderiam ser mais hostis. Cabe lembrar ainda os arranjos familiares e afetivos que lhes permitem manter $\mathrm{o}$ contato com suas raízes e "cuidar" delas à distância. Fato inegável, contudo, é que o grupo estudado é dupla ou triplamente marginalizado na sociedade em que se encontram. Tendo como fator preponderante para sua exclusão as de deslocamento suas "diferenças" que traduzem as marcas coloniais responsáveis por mantê-lo na subalternidade, cada vez mais vulneráveis e susceptíveis a discriminações.

O espaço da negritude e o espaço da mulher negra resultam cruzados com o espaço da imigração haitiana no Brasil contemporâneo, atualizando experiências sociais vividas na "precariedade das situações" (Gadea 2013:335) e na inconstância dos contextos de referência. Stuart Hall (2009) antecipara que categorias como "raça" e racismo precisam ser observadas tais como "práticas contextuais". Em si mesma, a categoria não é explicativa, apenas no interior de uma série de relações. Em suas múltiplas pertenças, o imigran- te ou a imigrante haitiano(a) negro(a) ocupa posições relativamente diferentes, embora, em nossa pesquisa, quase todas marcadas pela "diferença colonial" que inferioriza os homens e, ainda mais, as mulheres.

A "violência da colonialidade" (Mignolo 2003) refaz-se nas relações de poder em que se cruzam práticas, saberes e instituições provocando, como diz Foucault (1992) "efeitos de verdade". No Brasil, o movimento pendular passado-presente faz persistir a alteridade como o "não-branco", o não-europeizado - em última instância, o não-moderno, o não-sujeito, o "coisificado", usando a expressão de Aimé Cesaire, etc. - fabricado como subalterno.

Não podemos nos furtar em atentar que, em virtude de o Brasil ser um país de dimensões continentais, os dados e as análises apresentadas nesta pesquisa, se comparados a outra parte do território nacional, poderão sofrer algumas alterações, quer devido à região em que foi realizada a investigação, quer devido ao recorte espacial determinado pelos pesquisadores, ou mesmo pelas distintas experiências dos imigrantes haitianos que contribuem com a pesquisa. Neste contexto, importa salientar que tratamos de marcadores sociais produzidos, reproduzidos e metamorfoseados num contexto cultural e espacial determinado. Ainda assim, pensamos a imigração haitiana como um fenômeno exemplar das marcas (e "feridas", como aponta Mignolo, 2009) coloniais na modernidade tardia e revela o silenciamento sistemático da fala subalterna que não se restringe, muito provavelmente, ao campo aqui observado. 
Cabe, porém, uma referência aos estudos pós-coloniais (e ao "giro decolonial" latino-americano). Entendendo que tal empenho epistemológico dedica-se à releitura da produção cultural ideologicamente comprometida com o aparato colonial que persiste em corações e mentes, desconstruindo as representações que moldaram a alteridade (não-ocidental), também podemos supor que esta crítica potencializa a produção dos discursos e projeto de resistência, amplificando as vozes discordantes e expandindo os caminhos desviantes. Nesse sentido, trazer as vivências subalternas dxs imigrantes haitianxs negrxs em Porto Velho, à luz de reflexões descolonizadoras, é constatar a complexidade do funcionamento da colonialidade na modernidade contemporânea e é, também, se se tiver êxito na análise, constituir um contra-discurso em relação a algumas interpretações culturais tornadas hegemônicas.

\section{NOTAS}

${ }^{1}$ Durante o período colonial e no pós-independência, os haitianos emigravam, principalmente, em direção à França; às colônias francesas na África e ao Canadá de língua francesa. Os primeiros movimentos migratórios com destino aos Estados Unidos deram-se a partir de 1910, quando sua interferência política e econômica em território haitiano se intensifica. Logo, o Brooklyn se tornou a maior comunidade de haitianos em Nova Iorque. Entre as décadas de 1970 e 1980, milhares de haitianos emigraram para os Estados Unidos, oriundos da zona rural, com baixo nível de instrução e nenhuma proficiência no inglês. Chegavam em pequenas e precárias embarcações que ancoravam no sul da Flórida, onde entravam de forma indocumentada. A maior concentração de haitianos na Flórida deu-se ao nordeste de Miami, comunidade que passou a ser conhecida como Little Haiti. Neste período, porém o fluxo era tão intenso que muitos haitianos, abordados ainda nos barcos, foram deportados para o Haiti ainda quando solicitavam a condição de refugiados em razão dos assassinatos dos opositores ao regime ditatorial ou mesmo absoluta desproteção em face da violência reinante. Também, era comum, até o acirramento das críticas, a manutenção dos imigrantes haitianos na base militar americana de Guantánamo, em Cuba, que se transformara num campo de refugiados. Nos anos 1990, as mudanças políticas no Haiti diminuíram o êxodo, embora, as razões econômicas ainda determinassem a necessidade de que famílias se dividissem entre os que saíam do país e os que ficavam, na luta pela sobrevivência. Cf. Pierre-Louis 1998; Boina 2016.

${ }^{2} \mathrm{O}$ Haiti foi a primeira colônia negra a se tornar independente no mundo, em 1804, e a segunda no continente americano, somente posterior aos Estados Unidos. A então colônia indiana ocidental francesa, Saint-Domingue, assim chamada inicialmente, era a mais rica do período colonial e movimentava o comércio europeu, tanto de mercadorias quanto de escravos. Em 1791, dois anos após o início da Revolução Francesa, os haitianos começaram de forma mais intensa uma batalha sangrenta que durou mais ou menos doze anos até que, em $1^{\circ}$ de janeiro de 1804 , declarou-se o nascimento da república do Haiti. Nada seria fácil, porém, para a "Joia das Antilhas". Tendo que pagar uma abusiva indenização a França, sofrendo boicotes comerciais de todos os lados e intervenções diretas da Inglaterra, da Alemanha e dos Estados Unidos da América, em 1915, a ilha foi invadida pelos últimos a pretexto de não deixar 
que os alemães o fizessem. Ainda que se retirando oficialmente do Haiti em 1934, nunca mais os EUA deixaram de controlar o país. Sucessivas dinastias com seus governos ditatoriais sempre instáveis comandaram a nação, mais próximas ou menos dos interesses estadunidenses. O país convulsionado e empobrecido enfrentou, no século XXI, novos levantes militares, aos quais se somaram catástrofes ambientais como o terremoto de 2010 que provocou um número de óbitos superior a 200000 pessoas, além de cerca de 3 milhões de desabrigados. Cf. Boina 2016; Maus 2016.

${ }^{3}$ A expressão "democracia racial" surgiu no Brasil decorrente de algumas interpretações do livro Casa Grande e Senzala, de Gilberto Freyre (1997), publicado pela primeira vez, em 1933, marcando o pensamento social brasileiro.

${ }^{4}$ Gíria. Palavra associada por composição, contendo palavra de baixo calão, utilizada em certos grupos sociais para inferiorizar uma pessoa inconveniente. Estorvo. O xingamento era direcionado, como se nota, a um homem da "raça”" negra.

${ }^{5}$ Para preservar o anonimato, os nomes utilizados nesta seção não correspondem aos seus nomes verdadeiros.

${ }^{6}$ A última notícia que tivemos de Francine foi no ano de 2016, desde então, perdemos todos os contatos com haitiana.

7 "O conceito de articulação sugere relações de conexão e eficácia através das quais, como diz Hall 'as coisas são relacionadas tanto por suas diferenças como por suas semelhanças" (Brah 2006:353)

${ }^{8}$ Para efeito de nossas reflexões, utilizamos a palavra origem como uma forma de categorização, na qual se compreendem as origens étnicas, regionais ou nacionais.

9 A escritora chicana Glória Evangelina Anzaldúa, filha de camponeses do sul do Texas, teve sua família separada por uma fronteira imposta. Fazendo da leitura sua companhia nas jornadas de trabalho nas plantações, foi ativista desde jovem e, nos inícios dos anos 1970, conheceu a literatura feminista, iniciando sua produção literária no fim daquela década. Anzaldúa sabia da condenação ao silêncio da escrita feminina, sobretudo "mestiça", e, dentre outros, em "Falando em línguas: uma carta para as mulheres escritoras do terceiro mundo", escrito em 1980, apela às "mulheres de cor" às quais se dirige: "Não estamos reconciliadas com o opressor que afia seu grito em nosso pesar. Não estamos reconciliadas. Encontrem a musa dentro de vocês. Desenterrem a voz que está soterrada em vocês. Não a falsifiquem, não tentem vendê-la por alguns aplausos ou para terem seus nomes impressos. Com amor, Gloria”. Cf. Anzaldúa 2000.

\section{REFERÊNCIAS}

Anzaldúa, G. 2000. Falando em línguas: uma carta para as mulheres escritoras do terceiro mundo. Estudos Feministas 8 (1): 229-236.

Ballestrin, L. 2013. América Latina e o giro decolonial. Revista Brasileira de Ciência Politica 11: 89-117.

Bhabha, H. K. 2013. O local da cultura. Belo Horizonte: UFMG.

Brah, A. 2006. Diferença, diversidade, diferenciação, Cadernos Pagu 26: 329-365.

Boina, R. P. G. 2016. Literatura de migração, um espaço de memórias e representações. Dissertação de Mestrado, Departamento de Letras, UFES, Brasil.

Costa, C. L. 2014. Os estudos culturais na encruzilhada dos feminismos materiais e descoloniais. Revista Estudos de Literatura Brasileira Contemporânea 44: 79-103.

Cotinguiba, G. C., M. L. Pimentel. 2014. Wout, raketè, fwontyè, anpil mizè1: re- 
flexões sobre os limites da alteridade em relação à imigração haitiana para o Brasil. Universitas Relaçôes Internacionais 12: 73-86.

Crenshaw, K. 2002. Documento para o encontro de especialistas em aspectos da discriminação racial relativos ao gênero. Revista Estudos Feministas. 10.

Crenshaw, K. 2004. A intersecionalidade na discriminação de raça e gênero. Relações Raciais 1: 7-16.

Fanon, F. 2008. Pele negra máscaras brancas. Salvador: EDUFBA.

Fanon, F. 1980. Antilhanos e africanos, in Em defesa da revolução africana. Lisboa: Sá da Costa.

Freyre, G.. 1997. Casa-Grande \& Senzala. Rio de Janeiro/São Paulo: Record.

Foucault, M. 1992. Microfísica do poder. Rio de Janeiro: Graal.

Gadea, C. A. 2013. O espaço da negritude e o reverso da africanidade: crítica sobre as relações raciais contemporâneas, in Crítica pós-colonial. Panorama de leituras contemporâneas. Organizado por J. Almeida, A. M. Miglievich-Ribeiro \& H. T. Gomes, pp. 317-343 . Rio de Janeiro: Faperj/7Letras.

Glick-Schiller, N. e G. Fouron. 1997. Laços de Sangue: Os fundamentos raciais do estado-nação transnacional. Revista Crítica de Ciências Sociais 48: 33-66.

Handerson, J. 2015. Diáspora. As dinâmicas da mobilidade haitiana no Brasil, no Suriname e na Guiana Francesa. Tese de Doutorado, Antropologia Social, Museu Nacional/Universidade Federal do Rio de Janeiro, Brasil.

Maio, M. C. 1997. Uma Polêmica Esquecida: Costa Pinto, Guerreiro Ramos e o Tema das Relações Raciais. Dados. 40 (1). Rio de Janeiro.

Maldonado-Torres, N.. (2006). Against War. Durham/London: Duke University Press.
Maus, D. K. 2016. One Hundred Years of American Occupation in Haiti. Antillean Media Group 28. Disponível em: <http:/ / www.antillean.org/american-occupation-in-haiti-100/>. Acesso em 22 de dezembro de 2016.

Mignolo, W. 2003. Histórias locais/projetos globais. Colonialidade, saberes subalternos e pensamento liminar. Belo Horizonte: UFMG.

Mignolo, W. 2009. La idea de América Latina (la derecha, la izquierda y la opción decolonial). Crítica y Emancipación 2: 251-276.

Sayad, A. 2000. O que é um imigrante? In Blay, Eva Alterman. Imigração ou os paradoxos da alteridade. Revista de Antropologia 43: 253-256.

Schwarcz, L. M. 2007. Quase pretos, quase brancos: depoimento. Abril 2007. Pesquisa FAPESP. 134: 10-15. Entrevista cedida a Carlos Haag.

Schwarcz, L. M. 2009. Raça, in Diferenças, igualdade. Organizado por H. B. Almeida e J. E. Szwako. São Paulo: Berlendis \& Vertecchia.

Skidmore, T. 1976. Preto no branco: raça e nacionalidade no pensamento brasileiro. Rio de Janeiro: Paz e Terra.

Spivak, G. 2010. Pode o subalterno falar? Belo Horizonte: UFMG.

Taylor, C. 2000. Argumentos filosóficos. São Paulo: Loyola.

Wallerstein, I. M. 2006. Impensar a ciência social: os limites dos paradigmas do século XIX. Idéias \& Letras.

Recebido em 30/01/2017

Aprovado em 21/02/2017 